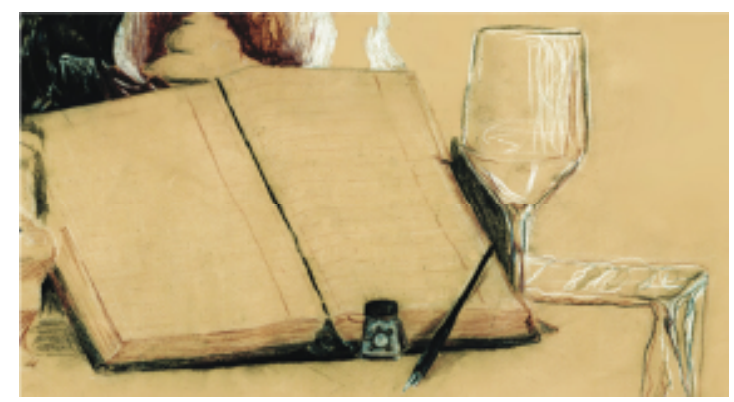

Ilustração Daniele ASCipriano

\title{
En el subte (metrô) uno puede ver casi siempre entre cinco $y$ diez personas por vagón que están leyendo un libro
}

\author{
Mario Camara \\ por Maria Antonieta Pereira
}

Mario Camara é editor da revista argentina Grumo.

Maria Antonieta Pereira é professora da Faculdade de Letras/UFMG e coordenadora do Programa A tela e o texto.

Maria Antonieta Pereira - Mario, tendo em vista sua trajetória como estudioso das culturas argentina e brasileira, como você percebe a leitura do texto impresso, especialmente das respectivas literaturas nacionais, em ambos os países?

Mario Camara - Un amigo de Río de Janeiro me decía que en Brasil hay más editoriales que librerías. Ese me parece un dato importante. Por otra parte, João Bandeira, cuando estaba al frente de la editorial de la USP, me decía que el ritmo de ediciones de novedades hacia muy difícil la reedición. La distribución y la reedición de libros son, por lo tanto, un problema en Brasil pero al mismo tiempo se tiene la impresión por la cantidad, por la calidad de la edición, que la industria editorial es, efectivamente, una industria que funciona. Entiendo que una industria editorial que funcione necesita de lectores. Por lo que puedo ver cada vez que viajo, la literatura brasileña se lee, circula y se produce. Sobretodo, ello sucede en el ámbito universitario y más precisamente en la posgraduación, en las maestrías y doctorados en Letras. 
Aquí en Argentina la situación es más precaria y más segmentada. Tenemos una proliferación importante de pequeñas y medianas editoriales, muchas de las cuales sólo distribuyen en unos pocos locales especializados de la ciudad de Buenos Aires. Se produce mucha poesía y se difunde de un modo más inteligente. Algunas editoriales medianas, por otra parte, están reeditando textos de autores como José Bianco, Juan Filloy o Sara Gallardo y con ello se están comenzando a cubrir importantísimos huecos y lagunas de nuestra historia literaria reciente.

Asimismo, es probable que aquí aún se lea un poco más, pero admito que es sólo una impresión. En el subte (metro) uno puede ver casi siempre entre cinco y diez personas por vagón que están leyendo un libro. También se lee mucho en los bares. Pero no necesariamente se lee literatura nacional y evidentemente no toda literatura producida por argentinos es buena. Hay mucha basura como Marcos Aguinis o Bucay que venden miles de ejemplares. Por otra parte, las ventas a veces no reflejan el nivel de lectura. El libro es un objeto de regalo y como tal se recibe y se archiva en algún rincón de la biblioteca.

Pero para resumir, creo que la crisis del año 2001 produjo algún grado mayor de adhesión por la lectura de autores nacionales. Piglia o César Aira son dos escritores que cuando editan un nuevo libro siempre venden $y$ son leídos $y$ comentados.

\section{Do ponto de vista histórico, que fatores levaram argentinos e brasileiros a terem níveis tão diferentes de leitura do texto impresso?}

Creo que un aspecto central de las diferencias, cada vez menores, estuvo dado por la llegada de editores españoles, catalanes más precisamente, que huían del franquismo y que rápidamente fundaron una industria editorial importante. Ello sumado a los bajos niveles de analfabetismo dio como resultado que por ejemplo en las décadas del sesenta y del setenta los niveles de venta y de circulación llegaran a niveles que hoy nos parecen increíbles. Hoy un poco añoramos eso y ese escenario, al mismo tiempo, nos moviliza.

En Brasil, creo que se parte de niveles más pobres y con altos índices de analfabetismo. Pero esa situación ha ido mejorando paulatinamente y creo que no se ha detenido ni se ha revertido hasta el presente. El desarrollo universitario es impresionante y las editoriales universitarias funcionan, al menos para un argentino, de modo ejemplar. 
Os níveis de alfabetização na Argentina e no Brasil contribuem para elevar (ou não) o consumo e a qualidade das obras literárias?

Entiendo que sí. Pero no hay que esperar milagros de la alfabetización, no al menos en términos de calidad literaria. La industria cultural, la sociedad del espectáculo de la que hablaba Guy Debord esta más pujante que nunca.

As discussões sobre a importância da tradição literária, levantadas por escritores como Borges e Macedonio, foram importantes para manter, em termos de América Latina, um bom nível de leitura dos argentinos?

Puede ser con Borges, que a partir de los sesenta comienza a transformarse en un escritor universal, citado por Foucault y traducido a decenas de lenguas, pero Macedonio Fernandez no deja de ser un escritor marginal, aunque extraordinario, editado, y eso muestra algo, por una pequeña editorial. Pero a los nombres mencionados se pueden agregar los de Puig, Cortázar y en el presente Piglia y Aira y entonces sí creo que podríamos decir que siempre hay algún grado de expectación o de esperanza de que Argentina produzca un buen escritor.

\section{Em termos da cultura das telas (cinema, vídeo, TV e computador), você acha que a leitura dos brasileiros é mais elaborada que a dos argentinos?}

Absolutamente. El otro día hablaba con Jorge La Ferla y me decía que Belo Horizonte es una de las ciudades más importantes del mundo en términos de producción de video. Lo que se llama el videoarte tiene un desarrollo que aquí directamente no existe. Además hay reflexión teórica y oferta académica. Arlindo Machado es una figura destacadísima y la residencia de Vilém Flusser en Brasil sin dudas ha contribuido al desarrollo de una reflexión sobre las relaciones entre arte, ciencia y tecnología.

No lo tengo tan claro en relación al cine. Creo que aquí hay una tradición interesante $y$ una crítica interesante. Desde comienzos de los noventa las revistas El Amante y Film contribuyeron a pensar el cine y luego, desde hace algunos años la proliferación de escuelas de cine $y$ el festival de cine independiente creo que nos colocan en una buena posición. 
No Brasil, os professores reclamam constantemente que "a televisão prejudica a leitura do livro". O que pensam sobre isso os professores argentinos?

Entiendo que la televisión perjudica si no se tienen herramientas de interpretación, si no se puede hacer una lectura crítica de lo que se ve. Por otra parte, no es lo mismo la televisión argentina que la brasileña. Las telenovelas brasileñas son productos muy interesantes, el programa de Jô Soares es magnifico. La percepción que tengo es que aquí hay un discurso contra la televisión, pero un discurso banal y prejuicioso. Creo que uno de los intentos más interesantes de reflexión sobre la tv lo realizó Tomás Abraham en la revista El Amante. Era una mirada con humor pero que no desatendía la especificidad del medio.

Em sua opinião, quais são as principais iniciativas de brasileiros e argentinos no sentido de resolverem os problemas de leitura das telas e dos textos em seus países?

Lamentablemente en Argentina, salvo esfuerzos aislados, no veo demasiadas iniciativas a nivel institucional. Las universidades no tienen el presupuesto que necesitan, la oferta de postgrados es muy pobre, las editoriales no tienen ningún subsidios, las revistas tampoco, no existe una ley de mecenazgo. Enfin, un panorama sombrío, que no es peor por la voluntad de mucha gente que trabaja gratis.

En Brasil, atención que me puedo equivocar como extranjero, veo una situación, como ya dije, que tiende a un desarrollo positivo. No pretendo con ello desconocer las tremendas desigualdades que atraviesan al país pero la creciente fortaleza de las universidades, el desarrollo de la industria editorial, la situación relativamente buena de los intelectuales me permiten ser cautamente optimista. 